\title{
My Life with Erwin: The Beginning of an Atom-Probe Legacy
}

\author{
J. A. Panitz ${ }^{1}$ \\ ${ }^{1 .}$ Department of Physics and Astronomy. The University of New Mexico. Albuquerque, NM.
}

The Atom-Probe Field Ion Microscope was introduced in 1967 at the 14th Field Emission Symposium in Gaithersburg, Maryland [1]. The Atom-Probe Field Ion Microscope was; and remains, the only instrument capable of determining "the nature of one single atom seen on a metal surface and selected from neighboring atoms at the discretion of the observer" [2]. The development of the Atom-Probe is a story of an instrument that one NSF reviewer called "impossible because single atoms could not be detected". It is also a story of my life with Erwin Wilhelm Müller as his graduate student in the Field Emission Laboratory at the Pennsylvania State University in the late 1960s and his strong and volatile personality, perhaps fostered by his pedigree as Gustav Hertz's student in the Berlin of the 1930s.

I joined the Field Emission Laboratory at Penn State as an Undergraduate Research Assistant shortly before receiving my B.S. degree in Physics in 1965. I quickly became aware of life in the laboratory as I prepared for my M.S. degree that I received in 1966. Erwin was well versed in photography and the art of scientific glassblowing, an art that I learned and practiced during my formative years [3-4]. Glassblowing was to serve me well as I prepared for what was to become my Ph.D. thesis: The AtomProbe FIM.

In the summer of 1966 Erwin returned from a trip to Europe with the concept of an "atom probe" in mind. He had met Raimond Castaing and coined the term Atom-Probe in analogy with the Electron Microprobe developed by Castaing in 1960 [5]. The Atom-Probe would combine the visibility of a single atom in a Field Ion Microscope [6] with a method to select the atom and then to analyze it in a magnetic sector mass spectrometer. Douglas Barofsky (Figure 1A) was completing his Ph.D. thesis using such an instrument and the timing was fortuitous. Doug was enrolled in an electron and ion optics course in which a time-of-flight (TOF) mass spectrometer was discussed. He convinced Erwin that the Atom Probe should incorporate a TOF spectrometer because; unlike a magnetic sector, it could display an extended range of masses.

When I started my Ph.D. project in 1966 I had to fabricate several glass parts including the glass-tometal seal at the end of a cold finger that would contain liquid hydrogen as a coolant (Figure 1B). But the real problem was the detector that had to have single atom sensitivity. Erwin said I should consider and then build an electron multiplier as the detector from scratch! After several attempts to fabricate curved dynodes from beryllium copper sheet (and a few cut fingers) I found that the dynodes from an EMI Photomultiplier Tube were commercially available. Fifteen dynodes were obtained and I constructed the single atom detector (Figure 1C). Of course, the Atom-Probe FIM was more than a detector and could not have been developed without the expert technical assistance of Brooks McLane and Gerry Fowler (Figure 1A).

In 1970 I joined the Sandia Laboratory in Albuquerque, New Mexico where I developed the $10 \mathrm{~cm}$ Atom Probe and the Imaging Atom-Probe. They became the progenitors of the atom probes that followed, including the commercial instruments available today and; as they say, the rest is history [7].

\section{References:}

[1] Erwin W. Müller and John Panitz. The 14th Field Emission Symposium. (1967), p. 31.

[2] Erwin W. Müller, John A. Panitz and S. Brooks McLane. Rev. Sci. Instrum 39 (1968), p. 83.

[3] Everyone in the laboratory referred to Erwin Wilhelm Müller as "Professor Müller". After I joined Sandia in 1970 I called him "Erwin" for the first time and he visibly flinched!

[4] Fusion: The Journal of the American Scientific Glassblowers Society. (May 1961), p. 21.

[5] R. Castaing, in Adv. Electronics Electron Phys. 13 (1960), p. 317. 
[6] Erwin W. Müller and Kanwar Bahadur. Phys. Rev. (1956), p. 102.

[7] J. A. Panitz. Progress in Surface Science 8 (1978), p. 219.

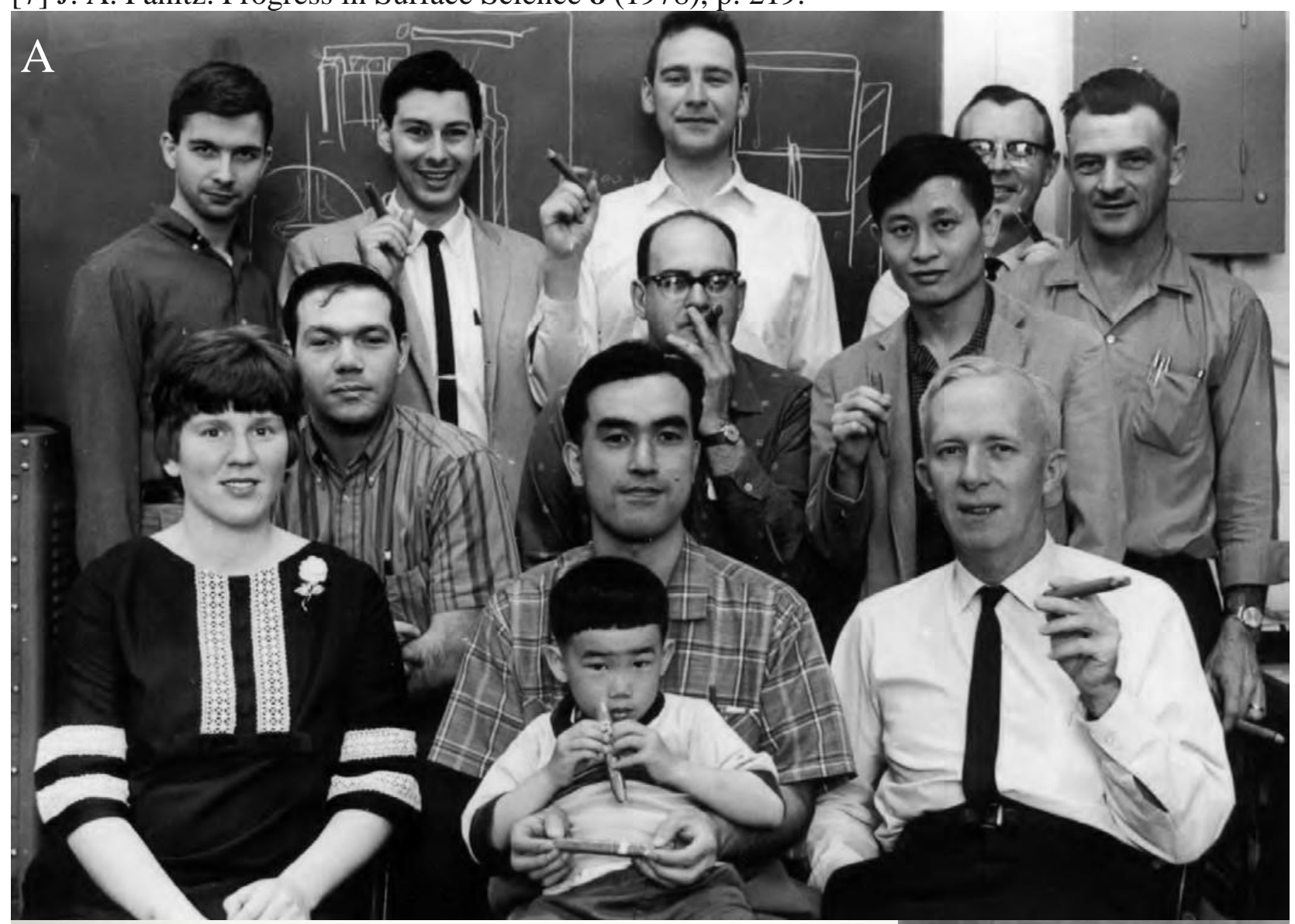

B
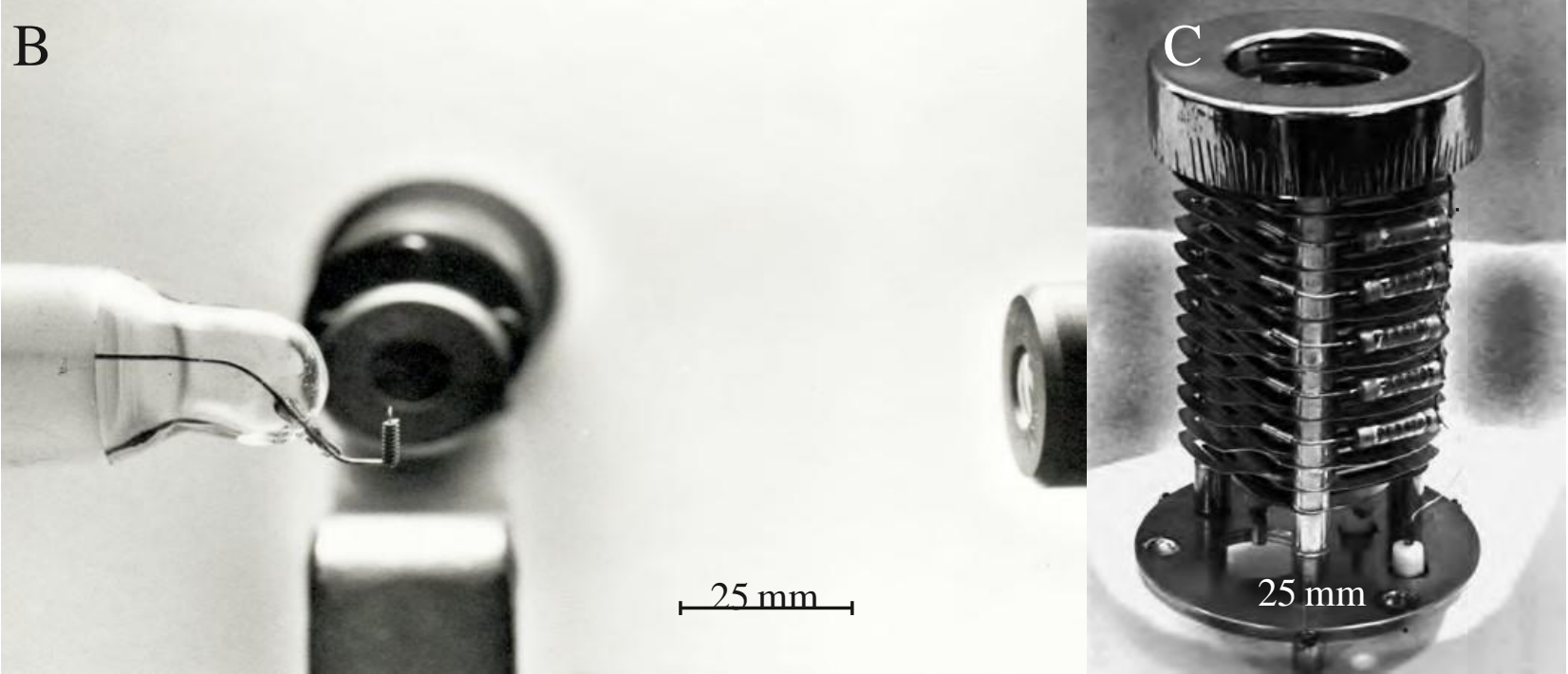

Figure 1. (A) A group photo taken in the Field Emission Laboratory at the Pennsylvanua State University in 1966. Top Row (left to right): John Panitz, Douglas Barofsky, Klaus Rendulic, Brooks McLane. Middle Row: Jay Politzer, Myron Hicks, Tien Tsong, Gerry Fowler. Bottom Row: Sandi Mori, Osamu Nisikawa with son Albert Noboru and Erwin Wilhelm Müller. (B) Glass-to-metal seal with a sample at the end of a cold finger in an optical alignment fixture used to position the sample. (C) The Atom-Probe Detector. 